\title{
EVALUATION OF REVERSAL EFFECTS OF EUGENIA JAMBOLANA SEED EXTRACTS AGAINST HIGH-FRUCTOSE DIET-INDUCED INSULIN RESISTANCE IN ALBINO RATS
}

\author{
M.H.R.K GUPATHA BAYYA ${ }^{1}$, SACHIDANANDA ADIGA MN ${ }^{2 *}$, NAGENDRA NAYAK IM ${ }^{3}$, ASITAVA DEB ROY ${ }^{4}$, \\ SAMPATH KUMAR AK ${ }^{5}$
}

${ }^{1}$ Department of Pharmacology, IQ City Medical College, Durgapur, West Bengal, India. ${ }^{2}$ Department of Pharmacology, K.S. Hegde Medical Academy, NITTE (Deemed to be University), Mangalore, Karnataka, India. ${ }^{3}$ Department of Pharmacology, K.S. Hegde Medical Academy, NITTE (Deemed to be University), Mangalore, Karnataka, India. ${ }^{4}$ Department of Pathology, IQ City Medical College, Durgapur, West Bengal, India. ${ }^{5}$ Department of General Medicine, K.S. Hegde Medical Academy, NITTE (Deemed to be University), Mangalore, Karnataka, India. Email: adigaiscool@yahoo.com

Received: 26 May 2018, Revised and Accepted: 31 July 2018

ABSTRACT

Objective: The objective of this study is to evaluate the reversal effects of aqueous and ethanolic extracts of jamun seeds against high-fructose (HFr) diet-induced insulin resistance (IR) in albino rats.

Methods: Thirty male albino rats were divided into five groups $(\mathrm{n}=6)$, and all the group rats except normal control were provided with $\mathrm{HFr}(60 \% \mathrm{w} / \mathrm{v}$ ) to their drinking water daily for 42 days. Group 1 and 2 served as a normal and fructose control. Groups 3, 4, and 5 were supplemented with metformin (MET 500mg/kg p.o) and aqueous and ethanolic extracts of jamun seeds (Jamun seed aqueous extract [JSAE] and Jamun seed ethanolic extract [JSEE] $1000 \mathrm{mg} / \mathrm{kg}$ of each p.o), from day 28 to day 42, respectively. Physical (body weights, food, and water intake) and biochemical (glucose, insulin, and lipid) parameters were estimated, and Homeostasis model assessment (HOMA)-IR values were calculated.

Results: HFr diet significantly $(\mathrm{p}<0.05)$ increased weight gain and water intake with decreased food intake in rats. HFr-fed rats exhibited a significant $(\mathrm{p}<0.05)$ increase in fasting glucose, insulin, and lipid levels along with increased HOMA-IR values and confirms the development of IR. Supplementation with MET, JSAE, and JSEE significantly $(p<0.05)$ restored the physical parameters and reversed fasting glucose and lipid levels in comparison with HFr control. Whereas, only JSAE had significantly reversed the fasting insulin levels in comparison with HFr control. HOMA-IR values were significantly $(\mathrm{p}<0.05)$ decreased in both the extract groups of HFr-fed rats, and the results were comparable to MET.

Conclusion: Our study concludes that both aqueous and ethanolic extracts of jamun exhibit a significant reversal effect against HFr diet-induced IR, due to insulin-sensitizing actions at the target tissues.

Keywords: Eugenia jambolana, Fructose, Insulin resistance, Hyperglycemia, Hyperlipidemia and Metformin.

(C) 2018 The Authors. Published by Innovare Academic Sciences Pvt Ltd. This is an open access article under the CC BY license (http://creativecommons. org/licenses/by/4. 0/) DOI: http://dx.doi.org/10.22159/ajpcr.2018.v11i12.27548

\section{INTRODUCTION}

Diabetes mellitus is a metabolic disorder characterized by chronic hyperglycemia either due to a deficiency of insulin secretion or a decrease in insulin sensitivity and/or both [1]. Type 2 diabetes often characterized by peripheral insulin resistance (IR) and insufficient functional mass of $ß$-cells [1,2]. Persistent hyperglycemia is often associated with long-term complications and had shown a significant impact on the quality of life and as well as on the health-care system [3]. According to the World Health Organization (WHO), the prevalence of type 2 diabetes will increase by up to 300 million by 2025 and could be due to lifestyle changes, consumption of calorie-rich diets, and obesity. India will be a diabetic capital of the world and sharing the global burden by 2025 [4-7].

IR develops due to the decrease in insulin action, insulin-stimulated glucose uptake, and dispose of the target tissues, often observed with hyperglycemia, hyperinsulinemia, and hyperlipidemia. IR is a central pathophysiological feature of type 2 diabetes and associated with dyslipidemia, obesity, hypertension, and atherosclerosis [8]. However, glucose intolerance in IR could be either due to the loss of insulin action or pancreas to induce hyperinsulinemia. IR owes to deregulate carbohydrate and lipid metabolism which are responsible for the oxidative stress that may lead to morbidity and mortality [9].

Fructose consumption has been dramatically increasing in the developed and industrialized nations. It is a lipogenic nutrient and commonly used as a sweetener in both food and pharmaceutical industries. Fructose is rapidly absorbed from the intestine and transported to the liver through the portal vein. Unlike glucose, fructose uptake and metabolism are not regulated by negative-feedback mechanisms in the liver [10,11]. Hence, long-term high-fructose ( $\mathrm{HFr}$ ) diet intake causes deleterious effects on body weight, glucose, and lipid metabolism, resulting in increased synthesis of fatty acids (FAs) and triglycerides (TGs) which impair insulin sensitivity and which lead to IR [12]. Feeding of rats with HFr $\operatorname{diet}(>60 \%$ of total calories) results in several metabolic abnormalities due to the modification of insulin action and signaling pathways. Therefore, the HFr diet is used as an animal model to induce either type-2 diabetes associated with IR or metabolic syndrome (MetS) [5].

Glitazones and biguanides are insulin-sensitizing agents which are commonly used in the treatment of IR. However, the use of glitazones was associated with several adverse effects such as weight gain, bladder cancer, fractures, and hepatotoxicity [2]. The WHO Expert Committee on Diabetes (1980) had recommended the use of traditional plants to reverse and/or prevent metabolic disorders. They are widely being used because of their effectiveness, less or no side effects, and relatively economical. In response to the pertaining problem, attempts were made to identify the plants that are having insulin-sensitizing as well as antihyperlipidemic effects. Therefore, need of a scientific evaluation of their efficacy in IR animal models may become extremely useful $[12,13]$. 
Eugenia jambolana (Family: Myrtaceae) is commonly known as jamun and widely distributed in India and the Asian countries. E. jambolana has shown various pharmacological activities which include antidiarrheal [14], gastric antisecretory [15], antioxidant [16], anti-inflammatory [17], antibacterial [18], anti-HIV [19], and neuropsychopharmacological [20] effects. Pre-clinical and clinical studies have shown that E. jambolana seed has antidiabetic and antihyperlipidemic activities [21-23]. According to a review of the literature, there is a lack of scientific work on insulin-sensitizing effects of jamun seed extracts on HFr diet-induced IR model. Hence, the present study was intended to investigate the reversal effects of jamun seed extracts on hyperinsulinemia, hyperglycemia, and hyperlipidemia in HFr diet-induced IR in rats.

\section{METHODS}

\section{Experimental animals}

Male Wistar Albino rats, initially weighing 240-300 g, were obtained from the animal house and maintained at $22 \pm 3^{\circ} \mathrm{C}$, humidity of $55 \pm 5 \%$, and $12 \mathrm{~h} / 12 \mathrm{~h}$ light-dark cycle with free access to food and water ad libitum. The experimental protocol (Ref.No: KSHEMA/IAEC/16/2015) was approved by the Institutional Animal Ethics Committee and followed the CPCSEA guidelines. Animal experimentation was carried only after 1 week of acclimation period. The study had been conducted in the Department of Pharmacology, K.S. Hegde Medical Academy (KSHEMA), Mangalore.

\section{Drugs and chemicals}

Fructose was procured from LOBA Chemie, Pvt., Ltd, Bengaluru. Metformin (MET) was supplied in the form of Glycomet Tablets, USV Ltd., Mumbai, and ketamine injection was obtained from Neon Laboratories Ltd., Mumbai, India. Both the glucose and lipid profile kits were purchased from Agappe Diagnostics, Kerala. Serum insulin kit was obtained from RayBio, Delhi. All the other chemicals and reagents used for the experimental purpose were of analytical grade.

\section{Plant extracts}

Both the aqueous and ethanolic extracts of E. jambolana (batch.no JFE/ D26/STD03 and STD04) were obtained from GreenChem, Bengaluru.

\section{Experimental design}

Male albino rats were randomly divided into five groups of six rats in each and provided with a standard pellet diet daily. All the rats except normal control received HFr diet $(60 \% \mathrm{w} / \mathrm{v})$ added to their drinking water for 42 days. Group 1 served as a normal control received gum acacia (2\%, p.o) and Group 2 served as $\mathrm{HFr}$ control received $\mathrm{HFr}$ $(60 \% \mathrm{w} / \mathrm{v})$ for 42 days. Groups 3, 4, and 5 received HFr supplementation with Metformin (MET $500 \mathrm{mg} / \mathrm{kg}$ ) and aqueous and ethanolic extracts of the jamun seed (JSAE and JSEE $1000 \mathrm{mg} / \mathrm{kg}$ of each), respectively, orally from day 28 to day 42 (Table 1). Blood samples were collected on days 1 and 42 under ketamine anesthesia from the overnight, fasted rats and centrifuged at 3,000 RPM for 10 min to carry out biochemical estimations.

\section{Biochemical estimations}

Blood glucose, total cholesterol (TC), TG, and high-density lipoprotein (HDL) levels $(\mathrm{mg} / \mathrm{dl})$ using the kit methods through Semi-Auto analyzer (Star 21 plus), respectively. Serum insulin $(\mu \mathrm{IU} / \mathrm{ml})$ was measured by Enzyme-Linked Immunosorbent Assay (ELISA) method, using an ELISA reader (Rapid Diagnostics Pvt., Ltd.). The biochemical analysis had been carried out in the Central Research Laboratory, KSHEMA, Mangalore.

Low-density lipoprotein cholesterol (LDL) was calculated according to the Friedewald's equation and very low-density lipoprotein cholesterol (VLDL) with TG/5 equation [24].

Homeostasis model assessment (HOMA)-IR was calculated by using the following equation [25]

HOMA-IR=Fasting insulin $(\mu \mathrm{IU} / \mathrm{ml}) \times$ Fasting glucose $(\mathrm{mg} / \mathrm{dl}) / 405$

\section{Determination of physical parameters}

Body weights

Weekly changes in their body weight of all group rats were recorded, and the weight gain of each rat was calculated by subtracting day 1 from the day 42 body weight.

\section{Food and water intake}

Daily food intake was calculated by deducting the amount of food left in the cage from the amount of food provided to each group, and the weekly average of daily food intake was calculated. Similarly, an average of daily water intake was also recorded.

\section{Statistical analysis}

Values are expressed as mean \pm standard error of the mean. One-way ANOVA followed by Tukey's multiple comparison tests, to assess the statistical significance with GraphPad prism. $\mathrm{p}<0.05$ was considered as statistically significant.

\section{RESULTS}

\section{Effect on body weight}

At the end of the study, all groups exhibited a significant $(\mathrm{p}<0.05)$ increase in their body weight and weight gain in comparison to normal control. Body weight and weight gain in HFr control were significantly $(p<0.05)$ increased from a normal control. Administration of MET significantly $(\mathrm{p}<0.05)$ reversed the increased body weight and weight gain as compared to $\mathrm{HFr}$ control. However, on HFr dietary supplementation with JSAE and JSEE for 14 days, failed to reverse increased body weight as compared to HFr control. There is no significant difference $(p>0.05)$ in a weight gain of JSAE but exists with JSEE as compared to MET (Figs. 1 and 2).

\section{Effect on food and water intake}

Long-term feeding of HFr diet significantly $(p<0.05)$ reduced food intake and increased water intake, in comparison to normal control. The MET significantly reversed $(\mathrm{p}<0.05)$ the reduced food intake and increased water intake in comparison to HFr control. Supplementation of HFr diet with JSAE and JSEE also reversed the reduced food intake and increased water intake in comparison to $\mathrm{HFr}$ control. Both jamun extracts did not exhibit a significant $(p>0.05)$ difference in food and water intake, except JSAE with MET (Figs 3 and 4).

\section{Effect on fasting glucose and insulin}

No significant $(p>0.05)$ difference was observed in the initial fasting glucose and insulin levels in all groups. Fasting glucose and insulin

Table 1: Experimental grouping

\begin{tabular}{lll}
\hline Groups.no & Groups (n=6) & Drugs and dosage \\
\hline Group 1 & Normal control & Water (2\% gum acacia, p.o) \\
Group 2 & HFr control & HFr $(60 \%$ w/v+2\% gum acacia, p.o) \\
Group 3 & MET & HFr+MET (500 mg/kg+2\% gum acacia, p.o) \\
Group 4 & JSAE & HFr+JSAE (1000 mg/kg+2\% gum acacia, p.o) \\
Group 5 & JSEE & HFr+JSEE (1000 mg/kg+2\% gum acacia, p.o) \\
\hline
\end{tabular}

MET: Metformin, HFr: High-fructose, JSAE: Jamun seed aqueous extract, JSEE: Jamun seed ethanolic extract 


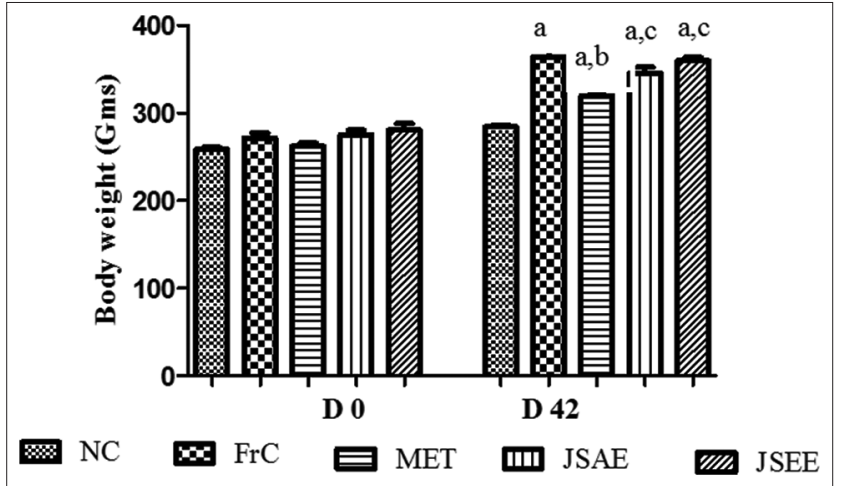

Fig. 1: Effect of aqueous and ethanolic extracts of E. jambolana seeds on body weights in high-fructose (HFr) diet-induced insulin resistance rats. Data are expressed as mean \pm standard error of the mean. $a, b$, and $c$ mean significantly $(p<0.05)$ different as compared with normal control, $\mathrm{HFr}$ control, and metformin groups, respectively, on the day 42

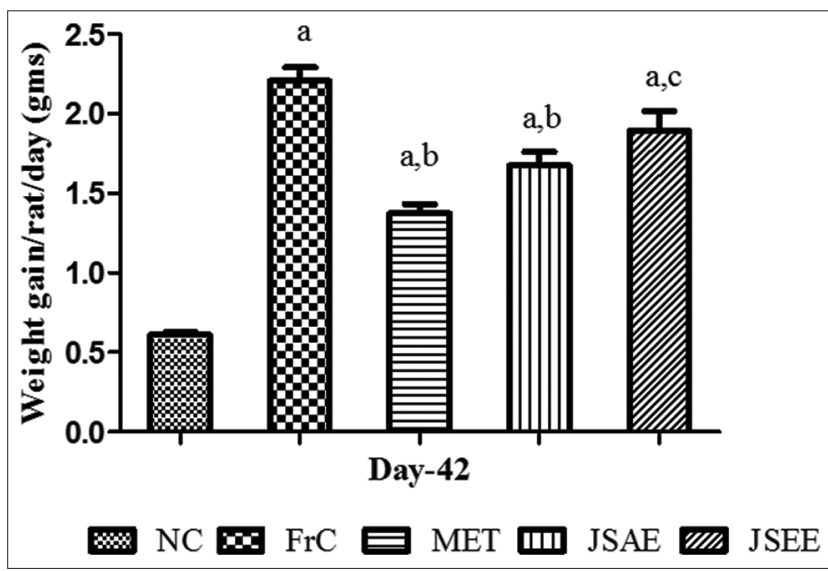

Fig. 2: Effect of aqueous and ethanolic extracts of E. jambolana seeds on weight gain in high-fructose $(\mathrm{HFr})$ diet-induced insulin resistance rats. Data are expressed as mean \pm standard error of the mean. $a, b$, and $c$ mean significantly $(p<0.05)$ different as compared with normal control, $\mathrm{HFr}$ control, and metformin groups, respectively, on the day 42

levels were significantly $(\mathrm{p}<0.05)$ elevated in HFr control as compared to normal control, indicating the establishment of hyperglycemia and hyperinsulinemia of IR in rats. However, administration of MET significantly $(p<0.05)$ reversed the fasting glucose and insulin levels as compared to HFr control, and the results were comparable to normal control, concerned with the glucose levels. It was observed that increased fasting glucose levels were significantly $(\mathrm{p}<0.05)$ reversed by feeding HFr supplementation with JSAE and JSEE, as compared to HFr control, and also exhibit significant $(\mathrm{p}<0.05)$ differences with normal control and MET group. JSAE has reduced fasting insulin levels as compared to $\mathrm{HFr}$ control, and both the extracts exhibit significant differences $(\mathrm{p}<0.05)$ with normal control and MET group (Table 2).

\section{Effect on IR index}

HFr control rats exhibited a significant $(\mathrm{p}<0.05)$ increase in HOMAIR values as compared to normal control, due to hyperglycemia and hyperinsulinemia at the end of the experiment. MET significantly $(p<0.05)$ reversed increased HOMA-IR values as compared to HFr control and exhibited comparable effects with normal control.Both the jamun extract groups, significantly $(\mathrm{P}<0.05)$ reversed the elevated HOMA-IR values as compared to HFr control group (Table 2).

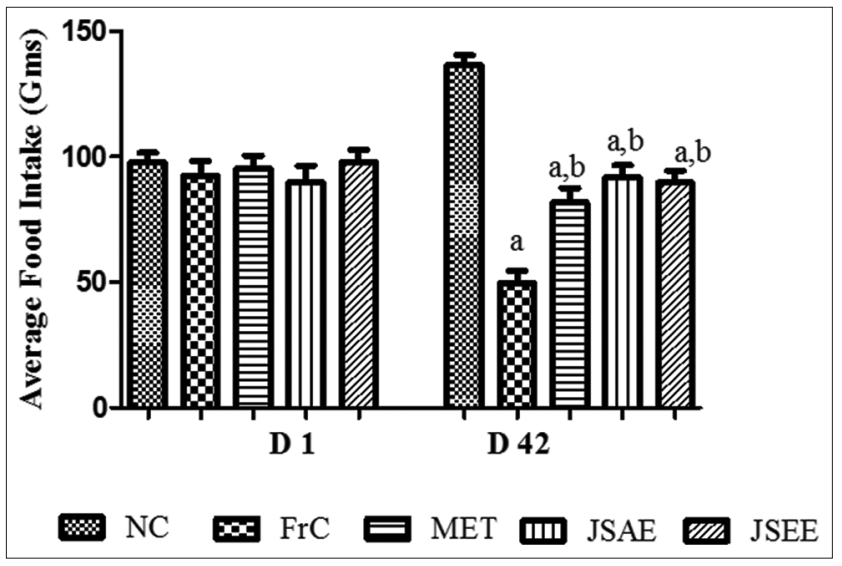

Fig. 3: Effect of aqueous and ethanolic extracts of $E$. jambolana seeds on average food intake in high-fructose (HFr) diet-induced insulin resistance rats. Data are expressed as mean \pm standard error of the mean. $a, b$, and $c$ mean significantly $(p<0.05)$ different as compared with normal control, HFr control, and metformin groups, respectively, on the day 42

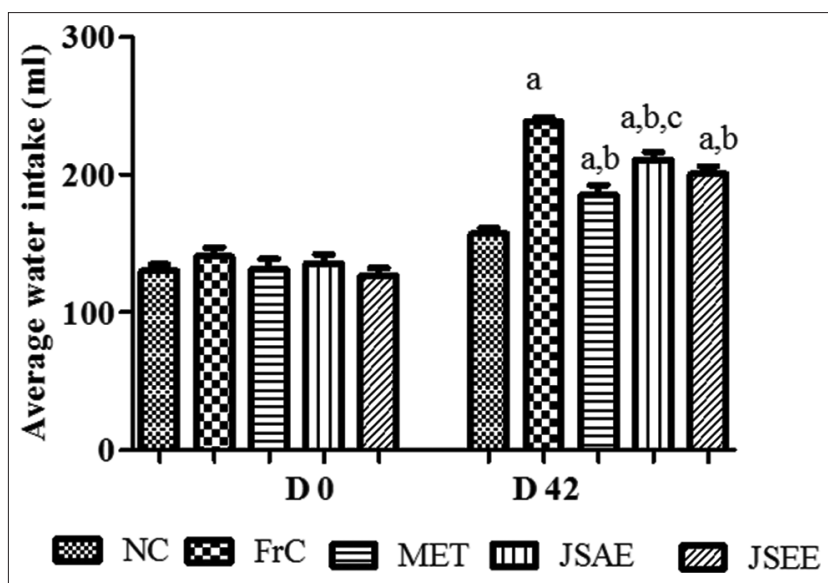

Fig. 4: Effect of aqueous and ethanolic extracts of $E$. jambolana seeds on average water intake in high-fructose (HFr) diet-induced insulin resistance rats. Data are expressed as mean \pm standard error of the mean. $a, b$, and $c$ mean significantly $(p<0.05)$ different as compared with normal control, $\mathrm{HFr}$ control, and metformin groups, respectively, on the day 42

Effect on lipid profile

HFr feeding significantly $(\mathrm{p}<0.05)$ increased TC, TG, VLDL, and LDL with decreased HDL levels in comparison to normal control and signifies the rise of hyperlipidemia associated with IR in rats. Administration of MET significantly $(\mathrm{p}<0.05)$ decreased TC, TG, VLDL, and LDL with a significant $(p<0.05)$ increase in HDL levels as compared to HFr control and also significantly $(\mathrm{p}<0.05)$ varies with normal control. HFr supplementation with JSAE and JSEE significantly $(\mathrm{p}<0.05)$ decreased TC, TG, VLDL, and LDL levels in comparison with HFr control and significantly $(p<0.05)$ differed with normal control. However, JSAE but not JSEE significantly $(p<0.05)$ restores the HDL levels and varies with normal control. Both extract groups exhibit comparable effects with the MET in reversing lipid abnormalities in HFr-fed rats (Tables 3 and 4).

\section{DISCUSSION}

IR is observed before the onset of diabetes and often aggravated by several factors such as genetic, lifestyle, obesity, other diseases, and drugs such as glucocorticoids and protease inhibitors [1]. Fructose intake increases the risk of diabetes, obesity, and non-alcoholic fatty liver disease [12]. 
Table 2: Effect of aqueous and ethanolic extracts of $E$. jambolana seeds on fasting glucose, insulin, and HOMA-IR in HFr diet-induced IR rats

\begin{tabular}{|c|c|c|c|c|c|c|}
\hline \multirow[t]{2}{*}{ Groups } & \multicolumn{2}{|c|}{ Fasting glucose (mg/dl) } & \multicolumn{2}{|c|}{ Fasting insulin $(\mu \mathrm{IU} / \mathrm{L})$} & \multicolumn{2}{|l|}{ HOMA-IR } \\
\hline & Day 1 & Day 42 & Day 1 & Day 42 & Day 1 & Day 42 \\
\hline Group 1 & $98.88 \pm 4.52$ & $113.92 \pm 4.88$ & $25.60 \pm 3.38$ & $28.23 \pm 3.4$ & $6.41 \pm 1.11$ & $8.08 \pm 1.19$ \\
\hline Group 3 & $87.02 \pm 6.21$ & $126.21 \pm 5.43^{\mathrm{b}}$ & $24.35 \pm 3.51$ & $65.26 \pm 5.26^{\mathrm{a}, \mathrm{b}}$ & $5.48 \pm 1.12$ & $20.61 \pm 2.46^{b}$ \\
\hline Group 4 & $100.32 \pm 4.79$ & $162.19 \pm 6.06^{\mathrm{a}, \mathrm{b}, \mathrm{c}}$ & $34.78 \pm 5.09$ & $94.13 \pm 6.32^{\mathrm{a}, \mathrm{b}, \mathrm{c}}$ & $8.9 \pm 1.66$ & $38.16 \pm 3.96^{a, b, c}$ \\
\hline Group 5 & $95.80 \pm 4.53$ & $170.29 \pm 7.14^{\mathrm{a}, \mathrm{b}, \mathrm{c}}$ & $30.73 \pm 4.87$ & $106.19 \pm 4.56^{a, c}$ & $7.5 \pm 1.44$ & $45.02 \pm 3.74^{a, b, c}$ \\
\hline
\end{tabular}

Data are expressed as mean \pm SEM. $a, b$, and c mean significantly $(\mathrm{p}<0.05)$ different as compared with mormal control, HFr control, and MET groups respectively on the day 42. E. jambolana: Eugenia jambolana, HOMA-IR: Homeostasis model assessment-insulin resistance, HFr: High fructose, SEM: Standard error of the mean, MET: Metformin

Table 3: Effect of aqueous and ethanolic extracts of E. jambolana seeds on fasting lipid profile (TC, TGs, and HDL) in HFr diet-induced IR rats

\begin{tabular}{|c|c|c|c|c|c|c|}
\hline \multirow[t]{2}{*}{ Groups } & \multicolumn{2}{|l|}{ TC } & \multicolumn{2}{|l|}{ TGs } & \multicolumn{2}{|l|}{ HDL } \\
\hline & Day 1 & Day 42 & Day 1 & Day 42 & Day 1 & Day 42 \\
\hline Group 1 & $73.35 \pm 2.78$ & $78.2 \pm 2.97$ & $50.7 \pm 4.66$ & $55.93 \pm 2.77$ & $48.07 \pm 2.49$ & $53.7 \pm 2.69$ \\
\hline Group 3 & $74.92 \pm 3.72$ & $125.51 \pm 6.2^{\mathrm{a}, \mathrm{b}}$ & $56.68 \pm 4.35$ & $132.37 \pm 4.24^{\mathrm{a}, \mathrm{b}}$ & $47.6 \pm 2.54$ & $34.91 \pm 3.1^{\mathrm{a}, \mathrm{b}}$ \\
\hline Group 4 & $77.09 \pm 4.55$ & $134.88 \pm 5.73^{a, b}$ & $51.98 \pm 3.29$ & $147.84 \pm 7.07^{\mathrm{a}, \mathrm{b}}$ & $49.52 \pm 4.09$ & $36.57 \pm 4.2^{\mathrm{a}, \mathrm{b}}$ \\
\hline Group 5 & $69.48 \pm 4.08$ & $146.5 \pm 6.17^{\mathrm{a}, \mathrm{b}}$ & $50.14 \pm 4.12$ & $160.02 \pm 6.87^{a, b, c}$ & $44.74 \pm 3.55$ & $31.85 \pm 2.47^{a}$ \\
\hline
\end{tabular}

Data are expressed as Mean \pm SEM. a, b, and c mean significantly ( $<<0.05)$ different as compared with normal control, HFr control, and MET groups, respectively, on the day 42. E. jambolana: Eugenia jambolana, HFr: High fructose, IR: Insulin resistance, TC: Total cholesterol, TG's: Triglycerides, HDL: High-density lipoprotein, SEM: Standard error of the mean, MET: Metformin

Table 4: Effect of aqueous and ethanolic extracts of $E$. jambolana seeds on fasting lipid profile (VLDL and LDL) in HFr diet-induced IR rats

\begin{tabular}{|c|c|c|c|c|}
\hline \multirow[t]{2}{*}{ Groups } & \multicolumn{2}{|l|}{ VLDL } & \multicolumn{2}{|l|}{ LDL } \\
\hline & Day 1 & Day 42 & Day 1 & Day 42 \\
\hline Group 1 & $10.14 \pm 0.93$ & $11.19 \pm 0.55$ & $15.13 \pm 1.68$ & $13.31 \pm 1.18$ \\
\hline Group 2 & $12.19 \pm 0.87$ & $44.28 \pm 1.59^{\mathrm{a}}$ & $14.11 \pm 1.6$ & $115.09 \pm 8.1^{\mathrm{a}}$ \\
\hline Group 3 & $11.34 \pm 0.87$ & $26.47 \pm 0.85^{\mathrm{a}, \mathrm{b}}$ & $15.98 \pm 0.93$ & $64.12 \pm 5.96^{\mathrm{a}, \mathrm{b}}$ \\
\hline Group 4 & $10.4 \pm 0.66$ & $29.57 \pm 1.41^{\mathrm{a}, \mathrm{b}}$ & $17.18 \pm 1.61$ & $68.75 \pm 6.92^{\mathrm{a}, \mathrm{b}}$ \\
\hline Group 5 & $10.03 \pm 0.82$ & $32 \pm 1.37^{\mathrm{a}, \mathrm{b}, \mathrm{c}}$ & $14.71 \pm 1.06$ & $82.64 \pm 3.18^{\mathrm{a}, \mathrm{b}}$ \\
\hline
\end{tabular}

Data are expressed as Mean \pm SEM. $a, b$, and c mean significantly $(\mathrm{p}<0.05)$ different as compared with normal control, HFr control, and MET groups, respectively, on the day 42. E. jambolana: Eugenia jambolana, HFr: High fructose, IR: Insulin resistance, VLDL: Very low-density lipoprotein-cholesterol,

LDL: Low-density lipoprotein-cholesterol, SEM: Standard error of the mean, MET: Metformin

Our study finding was supported by Mielke et al., who had stated that the HFr diet produces hippocampal IR. HFr diet $(60 \% \mathrm{w} / \mathrm{v})$ was most commonly used to induce hypertriglyceridemia, hyperinsulinemia, and hyperglycemia in hamsters, as reported by de Moura et al. and Suga et al. Among the various diabetic animal models, HFr diet mimics many symptoms of diabetes. Hence, this model has been used for the screening of effective and safer insulin sensitizers against IR [26-29].

In the present study, male rats were employed because female rats fail to develop IR with the HFr diet, probably due to the protective effects of the sex hormones in them $[9,30]$. Consumption of HFr diet significantly decreased food intake and increased calorie intake, (through fructose drinking water) promoted fat deposition, and weight gain in rats over a period. Excess calorie intake may be because of HFr that can alter leptin levels, play a significant role in regulating food intake and energy expenditure, thereby increase calorie intake, and encourage weight gain [31]. Both the MET and extracts restored water intake, due to decreased hyperglycemia and blood osmolarity which diminished stimulating effects on the hypothalamus and decreased polydipsia as observed in IR. Supplementation with JSAE extract effectively reduced weight gain in $\mathrm{HFr}$-fed rats by decreasing FA oxidation, and thereby reducing lipid storage in the tissues. Similarly, both the extracts have improved food intake by ameliorating insulin-sensitizing action and glucose abnormalities.

Hyperglycemia in HFr-fed rats was due to excess hepatic gluconeogenesis as a consequence of IR. Fructose increases the hexosamine pathway for glucose production, plays a crucial role in the development of IR and hyperlipidemia in rats. It does not stimulate insulin secretion directly, but the subsequent hyperglycemia with increased release of glucosedependent insulin tropic polypeptide and glucose like peptide-I from the intestine enhances insulin secretion contributes to hyperinsulinemia [6]. Fructose stimulates the $\beta$-cells to enhance insulin secretion and decreases insulin extraction by the liver with a delay in insulin clearance from circulation, leading to hyperinsulinemia [32]. The fasting glucose and insulin levels reflect HOMA-IR values and hence used to quantify the IR. A decrease in HOMA-IR values indicates the improvement of IS by reversing glucose and/or insulin concentration in HFr-fed rats[29,33]. In our study, HFr supplementation with MET and jamun extracts significantly reversed HOMA-IR values and exhibits antihyperglycemic effect through their insulin-sensitizing action rather than an increased insulin secretion.

In the liver, fructose increases the rate of de novo lipogenesis and TG synthesis. Hence, both TGs and free fatty acids (FFA) enhance the glycogenolysis, successively increase the hepatic glucose levels, and later lead to extrahepatic IR $[2,4]$. Before phosphofructokinase metabolizes fructose, it gets converted into glycerol and FFAs, which are taken up by the adipose tissue, leading to additional adiposity. The lipogenic nature of fructose increases the synthesis and release of atherogenic lipoproteins. Fructose-induced hyperglycemia also promotes lipid peroxidation and increases oxidative stress, which impairs insulin action at the cellular level. Hypertriglyceridemia and hypercholesterolemia are the most important factors to increase the risk of coronary heart disease [34]. Either increased HDL or decreased oxidized LDL levels will improve endothelial dysfunction by enhancing nitric oxide production and offers protection against atherosclerosis, most commonly seen in IR with obesity [9,27]. Hence, the present investigation demonstrates that both MET and Jamun extracts exhibited antihyperlipidemic effects by decreasing TC, TG, and LDL with an increase in HDL levels except JSEE group. Therefore, jamun extracts can be used to reverse hyperlipidemia in IR patients, according to ATP III guidelines. 


\section{CONCLUSION}

The promising results have shown that both jamun extracts can mitigate the hyperglycemia, hyperlipidemia, and hyperinsulinemia by improving insulin action at the target tissues, with a decrease in HOMA-IR index in HFr-fed rats. Hence, the study concludes that the reversal effects of jamun extracts were similar to insulin-sensitizing actions of MET and advised as a food supplement in IR patients associated with metabolic abnormalities.

\section{ACKNOWLEDGMENT}

We are thankful to Dean and Professor and Head of Pharmacology, KSHEMA, NITTE (Deemed to be University), Mangalore, for providing facilities to carry out research work. We appreciate the Central Research Laboratory for their extensive support in carrying the present work. We are also grateful to GreenChem, Bengaluru, for providing us jamun seed extracts as a gift sample.

\section{CONFLICTS OF INTEREST}

All authors had declared no conflicts of interests.

\section{AUTHORS' CONTRIBUTION}

The present work was carried out with the cooperation between all the authors. The two first authors Mr. B. Gupatha and Dr. S. Adiga were the principal investigators of the experimental study. Dr. Nayak, Dr. Asitava, and Dr. S. Kumar were contributed in the selection of drugs, plants, data analysis, and drafting of the manuscript. All authors reviewed and approved the manuscript for intellectual content.

\section{REFERENCES}

1. Agung EN, Mohamad A, Rina S, Arief N, Endang L, Suwijiyo P. Ethanolic extracts of A. Paniculata (burm. f.) Nees and its active compound, andrographolide, decrease the expression of glucose transporters (GLUT4) in high fructose-fat fed rats. Int J Phytomed 2011;3:486-97.

2. Gupta R, Sharma AK. Anti-hyperglycemic activity of aqueous extracts of some medicinal plants on wistar rats. J Diabetes Metab 2017;8:752.

3. Savita P, Sudeep G, Arvind M, Rakesh M, Arvind KS. Antihyperglycemic and antidyslipidemic potential of Ipomoea batatas leaves in validated diabetic animal models. Int J Pharm Pharm Sci 2015;7:176-86.

4. Sharma SB, Rajpoot R, Nasir A, Prabhu KM, Murthy PS. Ameliorative effect of active principle isolated from seeds of Eugenia jambolana on carbohydrate metabolism in experimental diabetes. Evid Based Complement Alternat Med 2011;2011:789871.

5. Malarvili T, Veerappan RM, Hazzena BV. Effect of Achyranthes aspera seeds on lipid profiles in selected tissues of rats fed with high doses of fructose. J Pharm Res 2011;4:1769-71.

6. Basumata C, Kalita JC, Mohan P, Baruah KK. Anti-diabetic effect of Cissampelos pareira Linn. On fructose-alloxan diabetic rats. Int J Int Sci Inn Tech Sec 2012;1:27-38.

7. Swayam PS, Akansha M, Vijai L, Akhilesh KT, Mahendra NS, Arvind KS. Antidiabetic and antidyslipidemic activity of ethyl acetate fractions of Xylocarpus granatum and Xylocarpus molluccensison high fructose high fat and high sucrose high fat fed-low dosed streptozotocin treated diabetic rats. Int J Pharm Pharm Sci 2015;7:537-43.

8. Kushwah AS, Patil BM, Thippeswamy BS. Effect of Phyllanthus fraternuson fructose induced insulin resistance in rats. Int J Pharm 2010;6:624-30.

9. Shawky NM, Shehatou GS, Abdel Rahim M, Suddek GM, Gameil NM. Levocetirizine ameliorates high fructose diet-induced insulin resistance, vascular dysfunction and hepatic steatosis in rats. Eur J Pharmacol 2014;740:353-63.

10. Sil R, Ray D, Chakraborti AS. Glycyrrhizin ameliorates insulin resistance, hyperglycemia, dyslipidemia and oxidative stress in fructose-induced metabolic syndrome- $\mathrm{X}$ in rat model. Indian J Exp Biol 2013;51:129-38

11. Tranchida F, Shintu L, Rakotoniaina Z, Tchiakpe L, Deyris V, Hiol A, et al. Metabolomic and lipidomic analysis of serum samples following curcuma longa extract supplementation in high-fructose and saturated fat fed rats. PLoS One 2015;10:e 0135948.

12. Sudharshan RD, Pradeep HA, Srinivasa RA, IbrahimMD.Preventive effect of Anogeissus latifoliain high fructose diet induced insulin resistance and metabolic dyslipidemia. J Nat Sci Res2012;2:121-31.
13. Madhavi M, Kiran S, Ramesh D. Evaluation of antidiabetic, antihyperlipidemic and antioxidant activities of Acacia leucophloea in streptozotocin-nicotinamide induced Type 2diabetic in rats. Glob J Pharm 2014;8:64-72.

14. Mukherjee PK, Saha K, Murugesan T, Mandal SC, Pal M, Saha BP, et al. Screening of anti-diarrhoeal profile of some plant extracts of a specific region of West Bengal, India. J Ethnopharmacol 1998;60:85-9.

15. Chaturvedi A, Kumar MM, Bhawani G, Chaturvedi H, Kumar M, Goel RK, et al. Effect of ethanolic extract of Eugenia jambolana seeds on gastric ulceration and secretion in rats. Indian J Physiol Pharmacol 2007;51:131-40.

16. Ravi K, Ramachandran B, Subramanian S. Effect of Eugenia Jambolana seed kernel on antioxidant defence system in streptozotocin induced diabetes in rats. Life Sci 2004a; 75:2717-31.

17. Kumar A, Illavarasan R, Jayachandran T, Deecaraman M, Kumar RM. Anti-inflammatory activity of Syzygium cumini seed. Afr J Biotechnol 2008;7:941-3.

18. Bhuiyan MA, Mia MY, Rashid MA. Antibacterial principles of the seeds of Eugenia jambolana. Bangladesh J Biol 1996;25:239-41.

19. Kusumoto IT, Nakabayashi T, Kida H, Miyashira H, Hattari H, Namba T, et.al. Screening of various plant extracts used in ayurvedic medicine for inhibitory effects on human immunodeficiency virus Type 1 (HIV-I) protease. Phytother Res 1995;12:488-93.

20. Chakrabarty D, Mahapatra PK, Chaudhuri AK. A neuropsychopharmacological study of Syzygium cumini. Planta Med 1985;2:139-43.

21. Kohli KR, Singh RH. A clinical trial of Jambu(Eugenia jambolana) in non-insulin dependent diabetes mellitus. J Res Ayurveda Siddha 1993;14:89-97.

22. Grover JK, Vats V, Rathi SS. Anti-hyperglycemic effect of Eugenia jambolana and Tinospora cordifolia in experimental diabetes and their effects on key metabolic enzymes involved in carbohydrate metabolism. J Ethnopharmacol 2000;73:461-70.

23. Gohil T, Pathak N, Jivani N, Devmurari V, Patel J. Treatment with extracts of Eugenia jambolana seed and Aegle marmelos leaf extracts prevents hyperglycemia and hyperlipidemia in alloxan induced diabetic rats. Afr J Pharm Pharm 2010;4:270-5.

24. Nayak Y, Venkatachalam H, Daroji VK, Mathew G, Jayashree BS, Unnikrishnan MK, et al. Antidiabetic activity of 3-hydroxyflavone analogues in high fructose fed insulin resistant rats. EXCLI J 2014;13:1055-74.

25. Samadi Noshahr Z, Shahraki MR, Ahmadvand H, Nourabadi D, Nakhaei A. Protective effects of Withania somnifera root on inflammatory markers and insulin resistance in fructose-fed rats. Rep Biochem Mol Biol 2015;3:62-7.

26. Mielke JG, Taghibiglou C, Liu L, Zhang Y, Jia Z, Adeli K, et al. A biochemical and functional characterization of diet-induced brain insulin resistance. J Neurochem 2005;93:1568-78.

27. de Moura RF, Ribeiro C, de Oliveira JA, Stevanato E, de Mello MA. Metabolic syndrome signs in wistar rats submitted to different highfructose ingestion protocols. Br J Nutr 2009;101:1178-84.

28. Suga A, Hirano T, Kageyama H, Osaka T, Namba Y, Tsuji M, et al. Effects of fructose and glucose on plasma leptin, insulin, and insulin resistance in lean and VMH-lesioned obese rats. Am J Physiol Endocrinol Metab 2000;278:E677-83.

29. Papiya B, Ravi N, Shekhar SC. Preventive effect of sesame seed cake on hyperglycemia and obesity against high fructose-diet induced Type 2 diabetes in rats. Food Chem 2012;133:1355-61.

30. Galipeau D, Verma S, McNeill JH. Female rats are protected against fructose-induced changes in metabolism and blood pressure. Am J Physiol Heart Circ Physiol 2002;283:H2478-84.

31. Ning CK, Huang PW, Wen HC, Yu CC, Hsien CH. Codonopsis javanica root extracts attenuate hyperinsulinemia and lipid peroxidation in fructose-fed insulin resistant rats. J Food Drug Anal 2013;21:347-55.

32. Kannappan S, Anuradha CV. Insulin sensitizing actions of fenugreek seed polyphenols, quercetin and metformin in a rat model. Indian J Med Res 2009;129:401-8.

33. Mohammadi A, Gholamhosseinian A, Fallah H. Trigonella foenumgraecum water extract improves insulin sensitivity and stimulates PPAR and $\gamma$ gene expression in high fructose-fed insulin-resistant rats. Adv Biomed Res 2016;5:54.

34. Mahmoud AM, Hozayen WG, Soliman HA, Mostafa SR. Enteromorpha flexuosa improves insulin sensitivity and metabolic control in fructoseinduced diabetic rats. J Endocrinol Diabetes Obes 2015;3:1072-82. 